\title{
A Research of Construct Discipline of Civil Aviation College Education Based on Employment
}

\author{
Qi Qi1, a, Honghu Jiang ${ }^{2, b}$ \\ ${ }^{1}$ Guangzhou Civil Aviation College, Guangzhou 510403, China; \\ 2 National Defence of Industry Press, Beijing 100048, China. \\ aqiqi@caac.net, b228651816@qq.com
}

\begin{abstract}
This paper proposes a new method to construct discipline of civil aviation college education by analysis CAAC's (Civil Aviation Administration of China) \& MOE's (Ministry of Education of China) documents. The author analysis the insufficiency of current student training, future professional needs and the discipline construction. The author suggest that the discipline construction should base on employment and students should own variety skills. The education curriculum should emphasize humanistic quality and learning ability. Teaching evaluation should be submitted with third parties and teaching objectives should be employment-based. Finally, the author put forward the idea of building industry-university-academia alliance.
\end{abstract}

Keywords: Employment orientation; Aeronautical service; the development path of subject specialty; Teaching evaluation system; Alliance of industry, education and research.

\section{以就业为导向的高职院校航空服务专业建设思路创新探究}

\author{
綦琦 ${ }^{1}$, 江洪湖 $^{2}$ \\ 1. 广州民航职业技术学院, 广州中国; \\ 2. 国防工业出版社, 北京 中国
}

摘 要: 本文分析民航局和教育部文件, 创新提出以就业为导向的高职院校航空服务专业建设 思路。分别从强化人才培养工作的内涵建设为办学升级夯实基础、我国航空服务专业人才将 长期供不应求和航空服务专业建设存在的发展误区分析发展现状, 开创性提出并分析了坚持 以就业为导向的专业发展思路、构建一专多能的专业课程教学体系、突出人文素质和再学习 能力的培养、基于第三方教学评价体系建设专业为目标的以就业为导向的航空服务专业发展 路径分析, 最后提出我国航空服务专业产学研联盟的设想。

关键词: 就业导向; 航空服务; 专业发展路径; 教学评价体系; 产学研联盟

\section{1. 前言}

2012年7月国务院颁布《关于促进民航业发展的若干意见》，明确指出民航业是我国经济社会 发展重要的战略产业, 又在第十七条中要求: 强化科教和人才支撑。强化民航院校行业特色, 鼓励有条件的非民航直属院校和教育机构培养民航专业人才。2014年3月, 教育部副部长鲁昕 在北京召开的全国职业教育工作会议上做了题为《加快构建以就业为导向的现代职业教育体 系, 为促进经济提质增效升级提供人才支撑》的讲话, 其中明确了 “以就业为导向” 是我国 高职教育服务国民经济发展、服务行业企业的目标。就业是结果，如何实现就业？我们认为 关键在于院校能培养出行业企业需要的人才, 而院校培养人才的能力归根结蒂在专业建设质 量。专业建设需要切实做到与时俱进、达到行业企业的标准，那么以就业为导向的目标也就 能实现。我们在此提出以就业为导向的高职院校航空服务专业建设思路创新的命题, 在此加 以研究并引发读者思考。 


\section{2. 我国航空服务专业人才将长期供不应求}

随着我国人均可支配收入持续增加, 公众对高品质出行需求日渐渴望, 加之各级政府对民航 业发展重视，我国民航持续安全、快速、健康发展。2017年，我国民航完成运输飞行1059.7 万小时, 同比增长 $11.6 \%$, 通航飞行 80.8 万小时, 同比增长 $6.2 \%$; 航空旅客运输量达 5.52 亿人 次, 同比增长 $13 \%$, 货邮量为 705.8 万吨, 同比增长 $5.7 \%$, 运输规模连续 12 年稳居世界第二。 相关机构预测 2018 年, 民航行业发展主要预期指标是: 运输总周转量 1208 亿吨公里、旅客运 输量 6.12 亿人次、货邮运输量 756 万吨, 同比分别增长 $11.6 \% 、 11.4 \%$ 和 $6.2 \%$; 全年航班平均正 常率不低于75\%。在民航资源供给方面, 截至2017年底, 我国运输航空公司运营运输飞机3296 架, 通用航空器2292架。运输颁证机场数量增至229个, 其中千万级机场达 32 个。北京首都国 际机场旅客吞吐量连续八年居全球第二; 上海浦东机场货邮吞吐量连续十年保持世界前三。 各地发展民航业的热情高涨, 据不完全统计目前全国共有65个城市, 依托57个机场规划了 64 个临空经济区。民航行业持续高速增长对专业人才的需求量持续递增。

民航归属于服务型行业。由于民航业务流程的特殊要求, 使得航空服务是一项极具专业性的 业务领域。我国民航正处于在全面发展的战略机遇期, 提升民航旅客服务质量是其中重要内 容之一。以航司、机场为代表的民航企业正不断探索着提升民航旅客服务质量的路径。我们 认为: 服务提升不只在于标准, 更在于执行标准的人本身。我国民航在今后的五到十年间, 对以空乘、地勤、安检、票务等岗位为代表的具有高素质、高技能的航空服务专业岗位将有 大量的人员增量和在职培训需求。目前, 我国民航直属院校只有五所, 况且他们更多的关注 飞行、空管、机务等民航特有技术型人才培养, 每年能向行业输出的以航空服务专业为代表 的服务型人才十分有限。预计今后非民航直属院校和教育机构将成为以航空服务专业为代表 的民航高技能服务型人才培养的中坚力量。

\section{3. 航空服务专业建设存在的发展误区}

随着民航行业被公众所了解和熟知, 进入民航行业企业工作成为了许多学生和学生家长的理 想和愿望。以航空服务为代表的旨在提升毕业生在民航岗位就业能力的专业成为我国众多院 校特别是高职层次院校新增开设或重点发展的专业, 非民航直属院校在航空服务专业招生占 比不断增加。但受制于内外部因素的局限, 我国各高职院校航空服务专业建设水平参差不齐, 毕业生质量难以保证, 甚至背离的为民航培养人才的初衷。具体发展误区主要体现在:

3. 1. 航空服务专业就是培养空乘

空乘可谓民航服务至高标准的形象代言人。和普通人提起民航, 大家首先想到的是飞行员和 空乘, 而空乘是旅客乘机可以直接接触到的。空乘职业社会认知的 “晕轮效应” 给航空服务 专业做了最好的广告, 但作为教育者, 我们要清醒地意识到航空服务和空中乘务的关系。什 么是航空服务专业? 培养以为民航运输产品的终端消费者（旅客或货主）提供直接服务民航 专业人才的教育实施单元。以此定义为标准, 参考民航特有工种国家职业标准的职业划分, 航空服务专业培养知识和技能的就业岗位指向于：民航乘务员、民航安检员、民航客运员、 民航售票员、民航货运员这五个工种。航空服务专业只是培养空乘显然是个伪命题。很多非 民航直属高职院校开设航空服务专业的初衷可能就是为了培养空乘, 为院校赢得社会的美誉 度和关注度, 但效果往往事与愿违。不尽人意的 “升空率” 成为时下众多院校的难题, 航空 服务专业发展似乎成为 “鸡肋”。

3.2. 重视硬件投入轻视软件建设

纵观我国各高职院校现行建设航空服务专业的模式: 领导开会定调一示范院校调研一照搬培 养方案一复制课程体系一采购模拟设备一建立实训基地。因此, 众多航空服务专业往往都 “师 出同门”, 更有甚者某些机构以硬件设备投入为条件参与院校空乘专业学生就业环节, 收取 高昂的 “培训” 费用。这种以培养空乘为目标的 “单一化” 的重 “硬件” 轻 “软件” 的专业 
建设模式已经严重制约了航空服务专业的良性发展。院校领导看到了大量的资源投入, 但是 收效甚微。

3. 3. 狠抓专业技能培养放手人文素质养成

民航行业的特殊性决定了其人才培养路径的独特性。以航司空乘选拔为例, 面试官看重的不 是应聘者具备多么专业的空乘岗位技能而是关注外形气质、个人素养、才队协作等人文素质。 究其原因, 航司均需要按照民航局CCAR121部的标准要求对学员进行系统化民航乘务员安全及 服务的专业知识和特殊技能培训, 学员之前的相应专业能力只能助力其接收效果快慢而非不 可或缺。从航司的角度而言, 专业技能是可以短时间培训出来的, 而人文素质却是需要长期 积淀的。目前, 航空服务专业建设中倡导大力强化专业技能忽视人文素质养成的现状显然与 行业需求是背道而驰的。

3. 4. 以主观的教育标准评价专业建设质量

关注什么就会做成什么, 评价什么就会发展什么。现有的专业建设质量评价体系是基于教育 标准而非行业标准。最大的问题就是院校培养出来的 “优秀人才” 无法达到行业企业的用人 标准。在航空服务专业升空的案例中, 恰恰是在学校专注于学习, 成绩优异的 “好学生” 无 法升空。我们需要打破现有主观的教育标准评价专业建设质量的 “惯性思维” , 在专业建设 中切实引入行业标准和采用第三方教学质量评价体系, 力争提升学生的核心就业能力。

\section{4. 以就业为导向的航空服务专业发展路径分析}

我们正是清晰看到现阶段我国航空服务专业发展问题的真正原因, 这为即将开始的坚持以问 题为导向创新高职院校航空服务专业建设提供了依据。我们综合航企需求和教学实践, 提出 以就业为导向的航空服务专业发展路径, 具体路径如下:

4. 1. 坚持以就业为导向的专业发展思路

专业建设质量的最终衡量标准是专业培养出毕业生的就业数量和质量。高职院校航空服务专 业是为民航行业企业培养高素质、高技能的专业人才, 专业发展必须紧紧依托行业、立足行 业。诚然, 现阶段我国非民航直属院校还缺乏直接了解我国民航发展动态的渠道, 但是这个 发展思路不能动摇。特别是各院校航空服务专业带头人要多走出校园、走进民航。我们也建 议引入第三方平台资源, 多组织民航直属和非直属院校的领导和老师交流, 相互学习、取长 补短, 共促航空服务专业发展的思路创新。

4. 2. 构建一专多能的专业课程教学体系

航空服务专业发展的 “单一空乘化” 是条死路。应该构建以针对民航乘务岗位要求为核心， 兼顾民航安检、民航客运、民航售票、民航货运等其它岗位要求为辅助的一专多能的专业课 程教学体系。认真做好人才培养的 “二八” 原则功课, 专业发展方向应是在力争提升专业毕 业生升空率的同时做好其向非空乘航空服务岗位分流的准备。培养出合适的人, 力争让适合 的人到合适的岗位上才是以就业为导向的专业建设的真正内涵。

4. 3. 突出人文素质和再学习能力的培养

针对航司在以空乘为代表的航空服务岗位招聘要求和培训安排, 航空服务专业建设应与时俱 进, 果断调整现有人才培养方案。整合现有的民航专业课程设置, 变知识传授和技能培养为 岗位认知和了解。我们提出基于民航行业标准针对航空服务具体工作岗位重新梳理航空服务 专业民航类课程的思路, 清晰界定院校教学和企业培训的专业知识范围, 减少民航类课程的 难度和学时。增加提升学生人文素质和再学习能力的教学环节和课程。军事化管理、穿制服 教学、专业化训练、形体化妆课、职业精神培养、餐饮茶艺技能等均是强化学生人文素质和 再学习能力的有效方法。

4. 4. 基于第三方教学评价体系建设专业

针对目前我国高职院校航空服务专业教学评价机制中存在的问题, 我们认为对专业教学质量 的评价不能仅由高职院校自身来担任评价主体, 而应该委托第三方评价机构进行客观教学评 价, 这也是国外教育界普遍使用的一种模式。建议由行业管理专家、行业技术专家、高职院 
校专家共同组成第三方评价主体, 通过引入民航特有行业岗位资格证书的考取等手段, 运用 发布我国高职院校航空服务专业建设质量蓝皮书的形式, 更加公正、公平、公开地推动专业 建设, 积极促进各高职院校航空服务专业建设工作的扎实推进, 共同增强专业毕业生的核心 就业竞争力。

\section{5. 关于我国航空服务专业产学研联盟的规划}

通过以上专业建设思路创新设计, 我们就以就业为导向的航空服务专业发展路径有了较清晰 的认知, 但是如何将这些事项具体落地, 特别是在非民航直属院校实施是相当有挑战的。我 们认为: 应该秉承互联网思维, 打破现有各院校闭门建专业, 掖着藏着打造自己的比较性优 势的狭险做法, 共同构建行业协会、民航企业、高职院校、出版机构、行业媒体、培训机构 等多方参与的航空服务专业产学研联盟。以此为平台构建起资源、信息、知识、技能高度共 享的航空服务专业发展的系统、科学、务实、高效地打通校企合作共同培养人才的 “最后一 公里”。

航空服务专业产学研联盟下设秘书处、航空服务专业建设咨询委员会和航空服务专业教学质 量评价委员会。秘书处负责民航行业发展信息和专业建设政策文件的汇总和发布、联盟的日 常性事务和会议组织; 咨询委员会负责制定、修订、研讨各联盟会员高职院校航空服务专业 全部资源供给; 评价委员会负责对会员高职院校航空服务专业建设进行年度第三方评价并汇 编我国航空服务及相关专业建设质量蓝皮书。

综上所述, 我国高职院校航空服务专业发展的目标是 “以就业为导向” ，实现这一目标的唯 一路径是 “打破陈规、创新发展”。

\section{References}

[1]. Qi Qi. On constructing civil aviation professional education industry chain. Air Transportation Business. Vol. 208(2007) No.11, p.9-12.

[2]. Qi Qi. Setting up innovative research on Chinese Regional Airport Line Work. Air Transportation Business.Vol.273 (2010) No.7, p.8-9.

[3]. Guangling Ma, Qi Qi, Xiaxin Xu. Civil aviation vocational education practice teaching system innovation research. Civil Aviation Management. Vol. 312(2011) No.12, p.93-96.

[4]. Guangling Ma, Qi Qi, Xinming Song. Reflections on the construction of transportation specialty organizations and activities of civil aviation work in Higher Vocational Colleges. Civil Aviation Management. Vol. 256(2012) No.2, p.94-96.

[5]. Xiaxin Xu, Qi Qi. The practice and exploration of the training of professional skills in the third party teaching evaluation system. The small and medium-sized enterprise management and technology. Management and science and technology of small and medium-sized enterprises. 2014. No.11, p.214-215.

[6]. Xu Xiao, Qing Wan, Qi Qi. The design and practice of online management of post practice in Higher Vocational Colleges. Value Engineering.Vol. 370(2015) No.1, p.258-259.

[7]. Xiaxin Xu, Qi Qi, Lei Xing. Research on innovative development course of international civil aviation ticket sales. Air Transportation Business. Vol. 359(2015) No.4, p.37-38.

[8]. Qi Qi.Intelligent Airport Planning Based on human based concept. China Civil Aviation.Vol. 203(2015) No.6, p.31-32.

[9]. Honghu Jiang, Qi Qi.An empirical study on the innovation model of the construction of professional high-quality materials for civil aviation transportation posts Air Transportation Business Vol. 371(2016) No.4, p.31-32. 
[10]. Information on: www.caac.gov.cn

[11]. Information on: www.carnoc.com.cn 